\section{Determining the optimal timing of screening spinal cord ultrasonography to detect filum terminale lipoma in infants}

\author{
Salman S. Albakheet ${ }^{1,2}$, Haesung Yoon ${ }^{1}$, Mi-Jung Lee ${ }^{1}$, Myung-Joon Kim', \\ Eun-Kyung Park ${ }^{3}$, Kyu-Won Shim³ ${ }^{3}$ Dong-Seok Kim ${ }^{3}$, Ho Sun Eun ${ }^{4}$, Kyunghwa Han ${ }^{1}$, \\ Hyun Joo Shin ${ }^{1}$
}

'Department of Radiology, Severance Hospital, Research Institute of Radiological Science, Yonsei University College of Medicine, Seoul, Korea; ${ }^{2}$ Department of Radiology, King Faisal General Hospital, Al-Hofuf, Saudi Arabia; ${ }^{3}$ Department of Pediatric Neurosurgery, ${ }^{4}$ Division of Neonatology, Department of Pediatrics, Severance Children's Hospital, Yonsei University College of Medicine, Seoul, Korea

Purpose: The purpose of this study was to identify the optimal timing for screening spinal cord ultrasonography (US) to detect filum terminale lipoma in infants.

Methods: We retrospectively reviewed infants ( $<12$ months old) who underwent repeated spinal cord US between April 2011 and January 2019. We excluded infants if they only had one US examination, or if they had lesions other than filum terminale lipoma. Infants with filum terminale lipoma on magnetic resonance imaging were included in the lipoma group and the others in the control group. A linear mixed model was used to assess differences in the growth pattern of filum terminale thickness by age and group. The cutoff thickness on US and its diagnostic performance were assessed according to age.

Results: Among 442 infants with 901 US examinations, 46 were included in the lipoma group and 58 in the control group. Sixty-seven infants had unmeasurable filum terminale thickness on initial US, including 55 neonates (82.1\%) before 1 month of age. The lipoma group had significantly greater filum terminale thickness than the control group $(P<0.001)$. Thickness increased with age in the lipoma group ( $\mathrm{P}=0.027)$. The sensitivity of US was $87.5 \%$ and the area under the receiver operating characteristic curve was 0.949 ( $95 \%$ confidence interval, 0.849 to 0.991) with a cutoff value of $1.1 \mathrm{~mm}$ in 4- to 6-month-old infants.

Conclusion: Screening spinal cord US could effectively diagnose filum terminale lipoma in 4- to 6-month-old infants with a cutoff thickness of $1.1 \mathrm{~mm}$. Spinal cord US can be used to screen young infants with intraspinal abnormalities.

Keywords: Infants; Spinal cord; Ultrasonography; Cauda equina; Retrospective studies

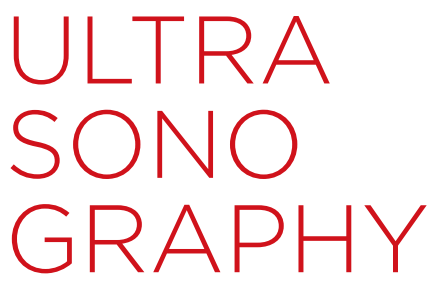

ORIGINAL ARTICLE

https://doi.org/10.14366/usg.19061 pISSN: 2288-5919 • elSSN: 2288-5943 Ultrasonography 2020;39:367-375

Received: October 24, 2019

Revised: March 16, 2020

Accepted: March 17, 2020

Correspondence to: Hyun Joo Shin, MD, PhD, Department of Radiology, Severance Hospital, Research Institute of Radiological Science, Yonsei University College of Medicine, 50-1 Yonsei-ro, Seodaemungu, Seoul 03722, Korea

Tel. +82-2-2228-7400

Fax. +82-2-2227-8337

E-mail: lamer-22@yuhs.ac

This is an Open Access article distributed under the terms of the Creative Commons Attribution NonCommercial License (http://creativecommons.org/ licenses/by-nc/4.0/) which permits unrestricted noncommercial use, distribution, and reproduction in any medium, provided the original work is properly cited.

Copyright @ 2020 Korean Society of Ultrasound in Medicine (KSUM)

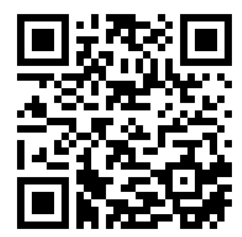

How to cite this article:

Albakheet SS, Yoon H, Lee MJ, Kim MJ Park EK, Shim KW, et al. Determining the optimal timing of screening spinal cord ultrasonography to detect filum terminale lipoma in infants. Ultrasonography. 2020 Oct;39(4):367-375. 


\section{Introduction}

Spinal lipomas, and particularly filum terminale lipomas, are among the most common causes of occult spinal dysraphism [1]. The filum terminale is a fibrovascular band that extends from the end of the conus medullaris to the internal aspect of the coccyx [2]. Despite some controversy regarding the clinical importance of lipomas in the filum terminale, they have been reported to cause tethered cord syndrome in pediatric patients $[3,4]$. A previous study reported that $97.2 \%$ of patients with occult tethered cord syndrome from a thickened filum had urological problems and that $60 \%-97 \%$ of cases showed improvements after a de-tethering operation $[5,6]$. Previous investigators suspected that fatty infiltration of the filum terminale would decrease the elasticity of the conus, ultimately leading to tethered spinal cord syndrome $[7,8]$. Pediatric patients with occult spinal dysraphism cannot present with a back mass or immediate neurological symptoms [9]. Therefore, accurate screening for filum terminale lipomas and early simple surgical interventions could prevent or decrease irreversible neurological deficits from tethered cord [10].

Spinal magnetic resonance imaging (MRI) is the imaging modality of choice for the diagnosis of filum terminale lipoma [11]. However, spinal cord ultrasonography (US) also plays an important role in screening for occult spinal dysraphism [12-15]. This is particularly true given the growing concern about filum terminale lipomas in infants with sacral skin dimples. US is used to detect and measure the thickness of the echogenic tubular tissue, which continues from the end of the conus medullaris in the lumbosacral dural sac [10]. As compared to spinal MRI, US has the benefit of a relatively short examination time with no need for sedation. However, no prior study has evaluated the optimal timing of screening US examinations of the spinal cord for filum terminale lipoma. Therefore, spinal cord US is currently performed at various time points, and often repeatedly in young infants. This disorganized practice may influence the accurate detection of lipomas using US, and lowers the effectiveness of the imaging modality.

Therefore, the purpose of this study was to evaluate the optimal timing of screening for filum terminale lipoma in young infants using spinal cord US.

\section{Materials and Methods}

\section{Subjects}

Institutional review board approval was obtained for this retrospective study. The requirement for informed consent was waived. A total of 596 neonates and infants ( $<12$ months old) who underwent repeated preoperative spinal cord US between
April 2011 and January 2019 were retrospectively included. Spinal cord US was performed to screen for cord tethering in infants with sacral dimpling, VACTERL syndrome, or hypospadias according to clinical needs. We excluded 148 infants who only received one US examination and six infants who had lesions other than filum terminale lipoma, such as lipomyelomeningocele, sacrococcygeal teratoma, or dermal sinus tract. Therefore, a total of 442 infants (male:female ratio $=222: 220$ ) with 901 US examinations were included in this study. The mean age of the infants at the initial US examination was $2.9 \pm 2.7$ months. One infant had 4 US examinations before 12 months of age. Fifteen infants had three US examinations, while 426 had two. The indications for US were as follows: sacral dimple $(n=426)$, hypospadias $(n=7)$, VACTERL syndrome $(n=8)$, and Down syndrome $(n=1)$.

\section{Spinal Cord US}

Spinal cord US was performed using the iU22 (Philips Healthcare, Bothell, WA, USA) with a 5-12 MHz linear transducer, or the Aixplorer (SuperSonic Imagine, Aix-en-Provence, France) with a 2-10 MHz linear transducer. Three board-certified experienced pediatric radiologists performed spinal cord US with infants in the left decubitus position. In the sagittal view of the lumbosacral spinal canal, the largest thickness $(\mathrm{mm})$ of the filum terminale was measured in an area with clear visualization of the dural sac and no bony shadowing or motion artifacts (Figs. 1-3). Two radiologists (S.S.A. and H.J.S.) reviewed the US images separately and recorded the thickness of the filum terminale by consensus. When the filum terminale could not be discriminated on the images, the thickness was recorded as 'unmeasurable' for that examination (Fig. 2A) and the reason for it was investigated. The presence of syrinx and lowlying conus medullaris with its end level below the lower endplate of the L2 vertebra was additionally recorded.

\section{Lumbosacral Spinal MRI}

Lumbosacral spinal MRI, including T1- and T2-weighted axial and sagittal images, was performed using a 1.5 or 3.0-T system (Intera Achieva, Philips Healthcare, Best, The Netherlands). MRI was selectively performed in infants who were suspected to have abnormalities based on US and according to neurosurgeons' clinical concerns. The acquisition parameters were as follows for T1weighted images: repetition time, $434 \mathrm{msec}$; echo time, $10 \mathrm{msec}$; flip angle, $90^{\circ}$; section thickness, $4 \mathrm{~mm}$; matrix size, 256×256; and field of view, $18 \mathrm{~cm}$. For the T2-weighted images, the acquisition parameters were as follows: repetition time, $4,800 \mathrm{msec}$; echo time, $100 \mathrm{msec}$; flip angle, $90^{\circ}$; section thickness, $4 \mathrm{~mm}$; matrix size, $320 \times 250$; and field of view, $18 \mathrm{~cm}$. Two radiologists (S.S.A. and H.J.S.), who were blinded to the clinical information, reviewed the 
MRI findings separately. The radiologists used the axial T1-weighted images to determine whether the patients had a lipoma on the filum terminale. The patients were included in the lipoma group if the filum terminale had high signal intensity on axial T1-weighted images. The remaining infants who underwent MRI examinations were included in the control group. Other features including syrinx, low-lying conus medullaris at the end level, and the presence of a vertebral segmentation anomaly were recorded based on MRI findings.

\section{Statistical Analyses}

Statistical analyses were performed using SPSS version 25.0.0 (IBM Corp., Armonk, NY, USA) and MedCalc version 18.2.1 (MedCalc
Software bvba, Ostend, Belgium). Because of the repeated measurements, a linear mixed model was used to compare the thickness of the filum terminale between the lipoma and control groups. The thickness was compared according to age group (0$3,4-6$, and 7-11 months) using the linear mixed model, because of the small number of infants in the groups. The differences and patterns of changes in the filum terminale thickness were evaluated according to age in the lipoma and control groups using the linear mixed model. When the thickness showed a significant change according to age, we assessed the monthly degree of growth using thickness measurements taken at the initial and last US examinations of each infant. In order to determine the optimal time period with a high sensitivity and accuracy for performing

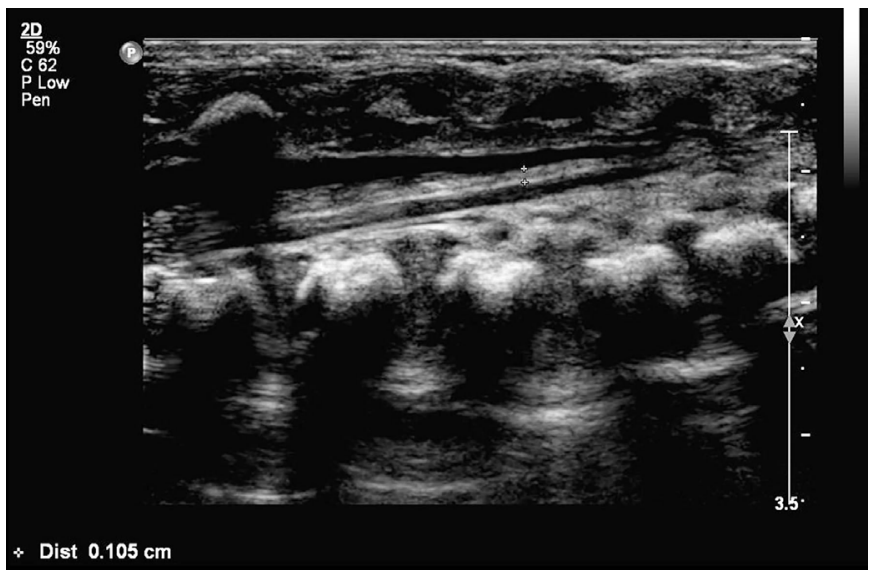

A

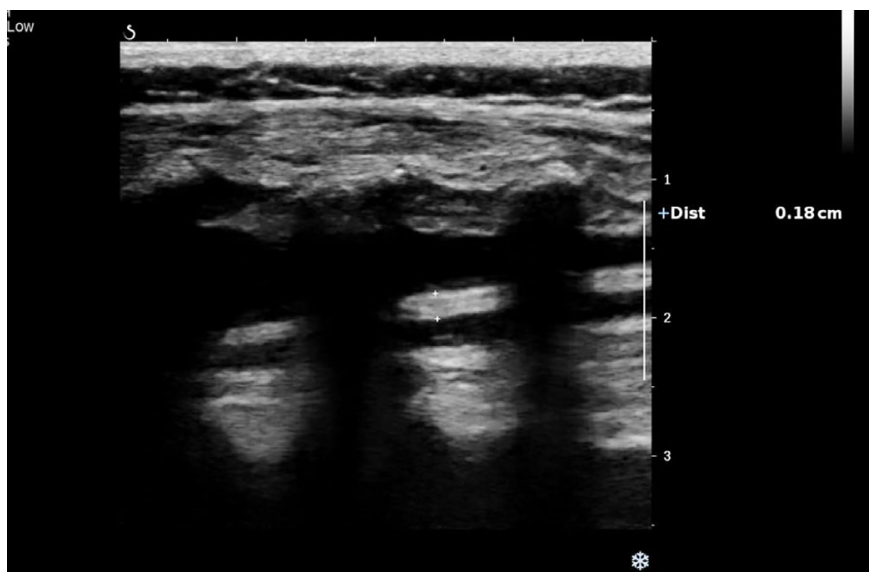

B

Fig. 1. The thickness of the filum terminale in a boy in the lipoma group.

A. Six days after birth, the filum terminale was $1.1 \mathrm{~mm}$ thick, corresponding to the cutoff value. B. At 5 months of age, the filum terminale thickness was $1.8 \mathrm{~mm}$ on ultrasonography, representing a lipoma.

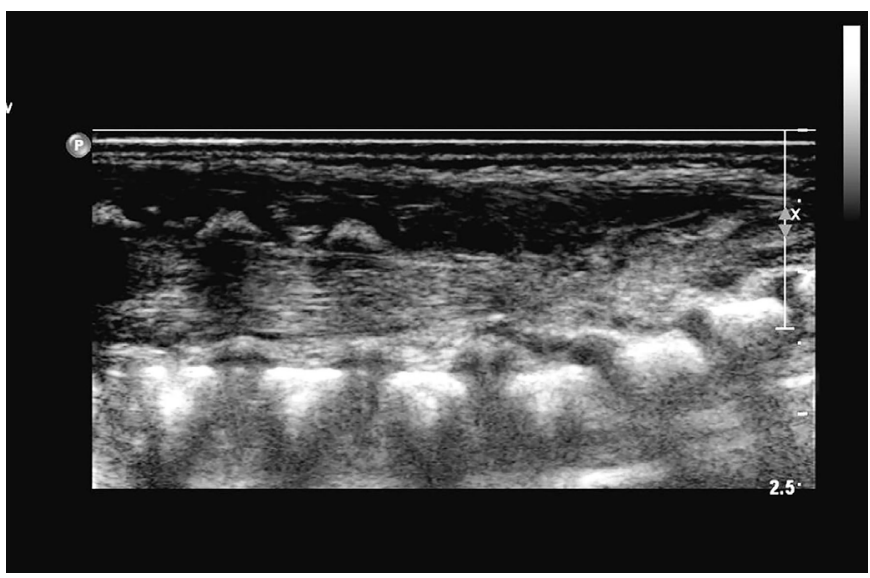

A

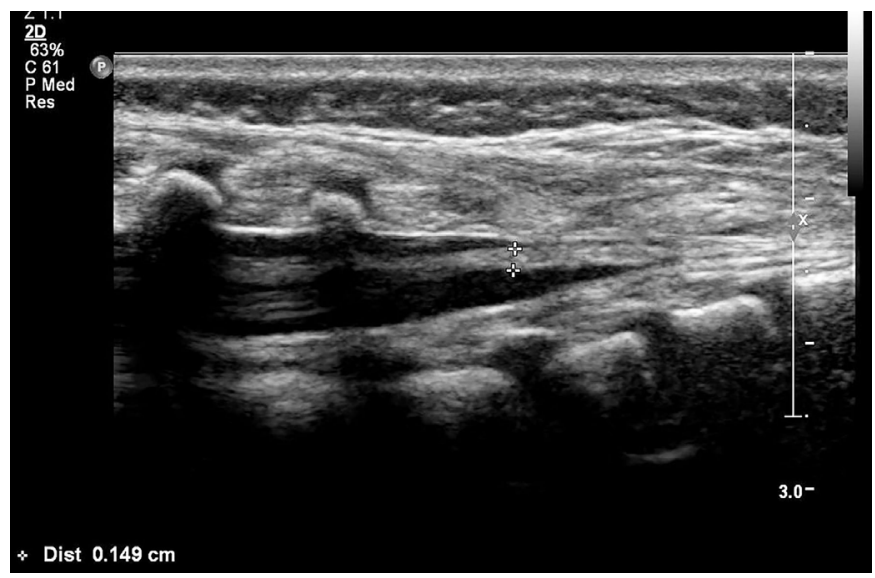

B

Fig. 2. The thickness of the filum terminale in a girl in the lipoma group.

A. Three weeks after birth, the thickness was unmeasurable due to crowding of the cauda equina, and we could not identify the filum terminale separately. B. At 3 months of age, the filum terminale was $1.5 \mathrm{~mm}$ thick, representing a lipoma. 
screening US, the cutoff value of the filum terminale thickness and its area under the receiver operating characteristic curve (AUC) were evaluated in all infants according to the same age groups. P-values of $<0.05$ were considered to indicate statistical significance.

\section{Results}

\section{Subjects}

Among the total 442 infants with 901 US examinations, 67 infants had an unmeasurable filum terminale thickness, including 55 neonates $(82.1 \%, 55$ of 67$)$ before 1 month of age, and all of these 67 infants were 6 months old or younger. None of the infants older than 6 months old had unmeasurable results (Fig. 3). The reasons for unmeasurable filum terminale thickness included crowding of the nerve roots in the lower lumbosacral canal and inability to distinguish the filum terminale from the cauda equina in 62 infants $(92.5 \%)$. The filum terminale in the remaining five cases was unmeasurable because of shadowing by the bony structures in the
US images. Ten of the 67 infants underwent MRI. Among them, one infant with an unmeasurable result on initial US had an increased thickness of the filum terminale on follow-up US and was found to have lipoma on MRI (Fig. 2). None of the remaining 57 infants who did not receive MRI examinations had a filum terminale thicker than $1.1 \mathrm{~mm}$ during US follow-up.

A total of 104 infants with mean age of 7.1 months (104 of 442, $23.5 \%$, with 222 US examinations) underwent MRI, of whom 46 (46 of 104, 44.2\%, with 94 US examinations) with filum terminale lipomas on MRI were included in the lipoma group. The remaining 58 infants were included in the control group. Additional features such as presence of syrinx, low-lying conus medullaris at the end level, or vertebral anomaly on US or MRI are summarized in Table 1. In the lipoma group, 33 infants (71.7\%) underwent surgery. Of the other infants who did not receive surgical treatment, eight infants did not undergo surgery in our hospital based on the parent's choice or loss of follow-up. Two out of the remaining five infants had constipation and urinary incontinence.

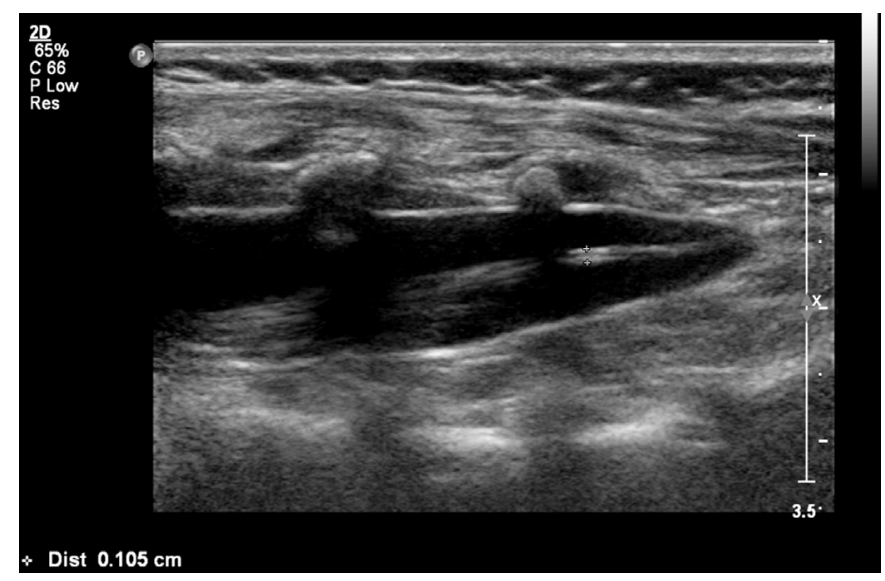

A

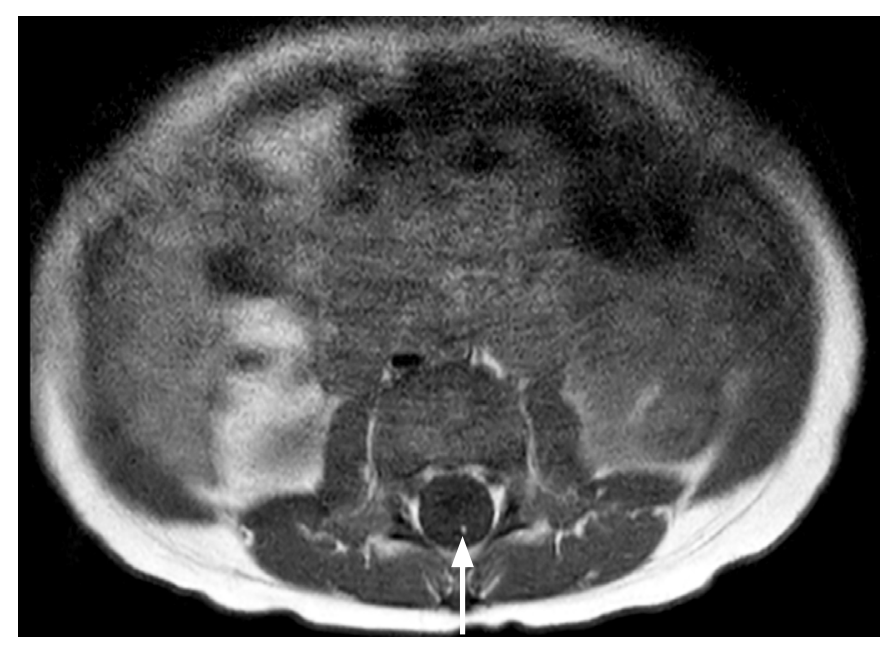

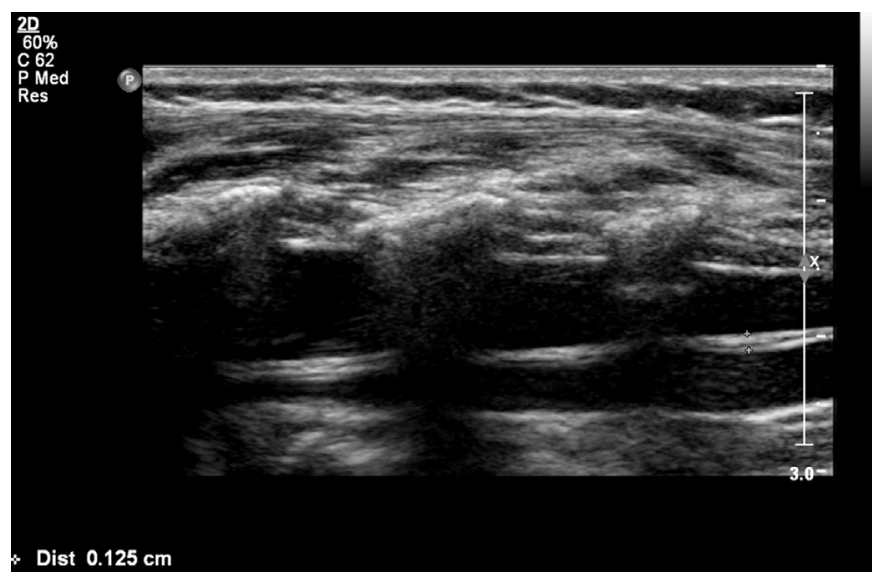

B

Fig. 3. The thickness of the filum terminale in a boy in the lipoma group.

A. At 7 months old, the thickness of the filum was $1.1 \mathrm{~mm}$. B. At 10 months old, the thickness was $1.3 \mathrm{~mm}$. Even though the infant was older than 6 months, spinal cord ultrasonography (US) revealed the cauda equina and filum clearly. C. On spinal magnetic resonance imaging performed 4 days after the last US exam, lipoma was seen as a high-signal-intensity lesion on the T1-weighted image (arrow). 
Differences in Filum Terminale Thickness According to Age and Group

The filum terminale thickness was significantly different between the lipoma and control groups $(P<0.001)$. In all age groups, the thickness of the filum terminale was significantly higher in the lipoma group than in the control group (all $\mathrm{P}<0.01$ ) (Table 2).

\section{Pattern of Changes in Filum Terminale Thickness according to Age and Group}

A significant difference in filum terminale thickness according to age was found in the lipoma group ( $P=0.027$ ), while no significant difference in thickness according to age was found in the control group ( $P=0.859$ ) (Fig. 4). The mean monthly growth rate of the filum terminale thickness was $0.14 \pm 0.19 \mathrm{~mm} / \mathrm{mo}$ in the lipoma group. The equation for thickness according to age in the lipoma group was as follows: Thickness $(\mathrm{mm})=0.05$ (Age in months) +1.39 .

\section{Cutoff Thickness of the Filum Terminale and Its Diagnostic} Performance for Screening US

The cutoff thickness value of the filum terminale to determine the presence of a lipoma on US in all infants was $1.1 \mathrm{~mm}$, with an AUC of 0.867 (sensitivity, $73.1 \%$; specificity, $89.1 \%$ ). The cutoff values and their diagnostic performance according to age are presented in Table 3. When we grouped the patients into three age ranges $(0-3$, $4-6$, and $7-11$ months), the sensitivity was $78.9 \%$ with an AUC of 0.869 (95\% confidence interval $[\mathrm{Cl}], 0.802$ to 0.920 ) using a cutoff thickness of $1.0 \mathrm{~mm}$ in 0 - to 3-month-old infants. In 4- to 6-monthold infants, the sensitivity was $87.5 \%$ and the AUC was $0.949(95 \%$

Table 1. Summary of imaging features of spinal cord US and MRI $(n=442)$

\begin{tabular}{|c|c|c|c|}
\hline \multirow[b]{2}{*}{ Variable } & \multirow{2}{*}{$\begin{array}{l}\text { Infants without MRI } \\
\qquad(\mathrm{n}=338)\end{array}$} & \multicolumn{2}{|c|}{ Infants with MRI $(n=104)^{a)}$} \\
\hline & & $\begin{array}{l}\text { Presence of filum terminale lipoma } \\
\text { (lipoma group, } n=46 \text { ) }\end{array}$ & $\begin{array}{l}\text { Absence of filum terminale lipoma } \\
\text { (control group, } n=58 \text { ) }\end{array}$ \\
\hline Unmeasurable filum terminale on initial US & 57 & $1^{\mathrm{b})}$ & 9 \\
\hline \multicolumn{4}{|l|}{ Thickened filum terminale (>1.1 mm) } \\
\hline Syrinx & 1 & $0(0)$ & $3(4)$ \\
\hline Vertebral anomalies & - & $-(1)$ & $-(2)$ \\
\hline
\end{tabular}

US, ultrasonography; MRI, magnetic resonance imaging.

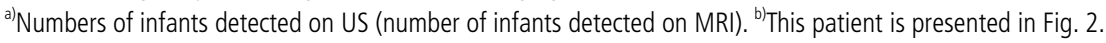

Table 2. Comparison of filum terminale thickness on ultrasonography (US) according to age

\begin{tabular}{|c|c|c|c|c|c|c|}
\hline \multirow[b]{2}{*}{$\begin{array}{l}\text { Age } \\
\text { (mo) }\end{array}$} & \multirow[b]{2}{*}{$\begin{array}{l}\text { No. of US } \\
\text { examinations in all } \\
\text { infants }\end{array}$} & \multirow{2}{*}{$\begin{array}{c}\text { No. of US } \\
\text { examinations in the } \\
\text { lipoma and control } \\
\text { groups }\end{array}$} & \multicolumn{3}{|c|}{ Thickness (mm), mean \pm SD } & \multirow[b]{2}{*}{$\begin{array}{c}\text { P-value between the } \\
\text { lipoma and control } \\
\text { groups }\end{array}$} \\
\hline & & & $\begin{array}{l}\text { Filum terminale in all } \\
\text { infants }\end{array}$ & $\begin{array}{l}\text { Filum terminale in the } \\
\text { lipoma group }\end{array}$ & $\begin{array}{l}\text { Filum terminale in the } \\
\text { control group }\end{array}$ & \\
\hline$<1$ & 277 & $36 / 30$ & $0.91 \pm 0.37$ & $1.47 \pm 0.58$ & $0.88 \pm 0.20$ & $<0.001$ \\
\hline 1 & 41 & $6 / 6$ & & & & \\
\hline 2 & 70 & $10 / 10$ & & & & \\
\hline 3 & 218 & $20 / 25$ & & & & \\
\hline 4 & 57 & $2 / 10$ & $0.92 \pm 0.30$ & $1.70 \pm 0.56$ & $0.98 \pm 0.19$ & $<0.001$ \\
\hline 5 & 64 & $4 / 12$ & & & & \\
\hline 6 & 93 & $10 / 13$ & & & & \\
\hline 7 & 28 & $1 / 8$ & $0.94 \pm 0.31$ & $1.58 \pm 0.53$ & $1.00 \pm 0.30$ & 0.007 \\
\hline 8 & 18 & $1 / 1$ & & & & \\
\hline 9 & 12 & $2 / 1$ & & & & \\
\hline 10 & 7 & $1 / 2$ & & & & \\
\hline 11 & 16 & $1 / 1$ & & & & \\
\hline
\end{tabular}




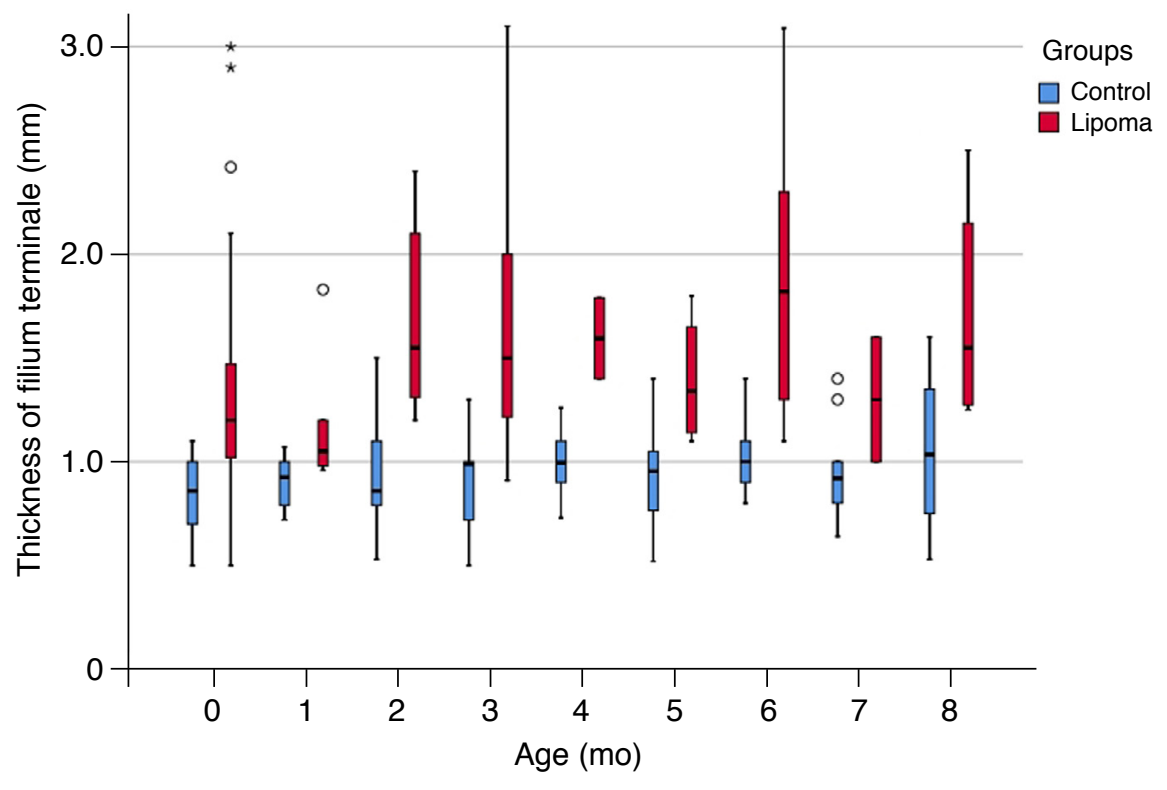

Fig. 4. Patterns of change in the filum terminale thickness $(\mathrm{mm})$ measured on ultrasonography according to age in the lipoma and control groups.

Table 3. The cutoff thickness of the filum terminale on US and diagnostic performance for lipoma detection by age

\begin{tabular}{|c|c|c|c|c|c|c|c|c|}
\hline Age (mo) & $\begin{array}{l}\text { Cutoff } \\
\text { thickness } \\
(\mathrm{mm})\end{array}$ & $\begin{array}{c}\text { Sensitivity } \\
(\%)\end{array}$ & $\begin{array}{c}\text { Specificity } \\
(\%)\end{array}$ & $\operatorname{AUC}(95 \% \mathrm{Cl})$ & $\begin{array}{l}\text { Cutoff } \\
\text { thickness } \\
(\mathrm{mm})\end{array}$ & $\begin{array}{c}\text { Sensitivity } \\
(\%)\end{array}$ & $\begin{array}{c}\text { Specificity } \\
(\%)\end{array}$ & AUC $(95 \% \mathrm{Cl})$ \\
\hline$<1$ & 1.05 & 71.4 & 96.7 & $0.853(0.744-0.929)$ & 1.0 & 78.9 & 84.5 & $0.869(0.802-0.920)$ \\
\hline 1 & 0.93 & 100 & 66.7 & $0.833(0.516-0.979)$ & & & & \\
\hline 2 & 1.10 & 100 & 80.0 & $0.940(0.737-0.997)$ & & & & \\
\hline 3 & 1.12 & 80.0 & 92.0 & $0.918(0.797-0.979)$ & & & & \\
\hline 5 & 1.00 & 100 & 75.0 & $0.906(0.656-0.993)$ & & & & \\
\hline 6 & 1.10 & 90.0 & 92.3 & $0.958(0.782-0.999)$ & & & & \\
\hline $7-8$ & 0.99 & 100 & 66.7 & $0.861(0.530-0.989)$ & 1.0 & 100 & 61.5 & $0.865(0.632-0.976)$ \\
\hline $9-11$ & 1.10 & 100 & 75.0 & $0.875(0.473-0.997)$ & & & & \\
\hline
\end{tabular}

US, ultrasonography; AUC, area under the curve; $\mathrm{Cl}$, confidence interval.

$\mathrm{Cl}, 0.849$ to 0.991$)$ when applying a cutoff thickness of $1.1 \mathrm{~mm}$. In 7- to 11 -month-old infants, the sensitivity was $100 \%$ with an AUC of $0.865(95 \% \mathrm{Cl}, 0.632$ to 0.976$)$ when applying a cutoff thickness of $1.0 \mathrm{~mm}$.

\section{Discussion}

Filum terminale lipomas are commonly occurring occult lesions in patients with congenital spina bifida that can cause thickening, loss of flexibility, and shortening and traction of the spinal cord, as well as provoking tethered cord syndrome [16-19]. Tethered cord syndrome is caused by diminished blood flow and impaired mitochondrial oxidative metabolism of the spinal cord [7]. This condition can subsequently cause irreversible neurological and urological dysfunction at the lumbosacral level in the form of pain, motor or sensory dysfunction, and neuro-orthopedic abnormalities $[20,21]$. Occult tethered cord syndrome from a thickened filum was recently proposed, but this possibility has yet to be thoroughly investigated [5]. Even though no consensus exists regarding the treatment of filum terminale lipoma, recent studies have demonstrated that the risk of neurological impairment in pediatric patients with filum terminale lipoma was higher than in adults, and early surgical detethering may prevent possible irreversible neurological deficits $[5,11,19,22-24]$. Consequently, we propose 
that the early detection of filum terminale lipoma is important, particularly for screening purposes in pediatric patients.

It is well-recognized that spinal cord US can be used as an easy screening tool for the detection of filum terminale lipoma by measuring the thickness of the filum terminale in young children. There is an increasing demand for screening spinal cord US to detect intraspinal abnormalities $[9,10,25]$. Although US cannot replace MRI for a definite diagnosis, it can be used to screen infants with skin stigmata, VACTERL syndrome, and urological or gait abnormalities, and to select infants who need lumbosacral MRI $[9,25]$. Previous studies have addressed the cutoff thickness for the diagnosis of filum terminale lipoma $[10,14,23,26-28]$. However, no prior study has determined the optimal timing of spinal cord US for the detection of filum terminale lipoma in young children.

In this study, we found that the thickness of the filum terminale increased with age in the lipoma group. The cutoff thickness for detecting a lipoma was $1.1 \mathrm{~mm}$ for all infants under 12 months of age, which is the same result as that of a previous study [10]. In 4to 6 -month-old infants, the sensitivity was $87.5 \%$ and the AUC was also high, at 0.949 . This result shows that screening spinal cord US was more effective in 4- to 6-month-olds than in 0- to 3-montholds. Most (82.5\%) unmeasurable results occurred in infants under 1 month of age, and $92.5 \%$ were unmeasurable because of spinal canal crowding. These results may be explained by the small spinal canal size and dehydration status of the neonatal period. No infants older than 6 months had unmeasurable results. Therefore, we suggest that screening spinal cord US is more effective in 4- to 6-month-old infants than in 0- to 3-month-old infants. In addition, this study also demonstrated that spinal cord US was an effective tool for screening young infants who needed spinal MRI due to suspected intraspinal abnormalities.

Explanations about the optimal timing of spinal cord US have been proposed in several previous studies. One group explained that spinal cord US is most useful in infants up to 6 months of age before the spine ossifies; this group performed US in infants up to 1 month of age [25]. Another study involved spinal cord US in infants up to the ninth week of age [9]. A review article that addressed the technique of spinal cord US in infants stated that although US can be performed in infants up to 12 months of age, the image quality declines markedly after 6 months due to bony maturation [29]. However, our study included 174 infants who were at least 6 months of age, and demonstrated that spinal cord US is possible after 6 months (Fig. 3). Of the infants with unmeasurable results, all were 6 months old or younger. The sensitivity in 7- to 11-month-olds was actually higher than the sensitivity in 0 - to 3 -month-olds, while the AUC was the same, at 0.87 . In addition, our study is the first to describe the technical difficulties of visualizing the filum terminale on US in the neonatal period and to present the optimal cutoff value for its thickness and the timing of measurements in a large number of infants. This study also revealed that the filum terminale thickness increased with age in the lipoma group. The detection of age-related changes may result from an increased number of spinal cord US examinations being performed with US techniques with a high spatial resolution. For this reason, if spinal cord US shows unmeasurable or borderline thickness results in the 0- to 3-monthold period, repeated US could be recommended when the infant is 4 to 6 months old because the thickness of the filum terminale increases with age in infants with lipoma and because there are fewer unmeasurable results in this age range overall. If the screening US results are positive according to the cutoff values for each age range, spinal MRI can be recommended for a definitive diagnosis.

This study has several limitations. First, because this was a retrospective study, MRI was selectively performed in infants who were suspected to have abnormalities based on US and according to the neurosurgeons' and parents' concerns. This factor led to heterogeneity in whether MRI was performed and in the frequency of repeated screening US for young children. Many infants $(n=338)$ who did not undergo MRI and had normal findings on spinal cord US were excluded from the control group. This could have led to selection bias. Second, we measured the filum terminale retrospectively using saved US images, which may have introduced some inaccuracies. In addition, concerns could be raised about the inaccuracy of submillimeter measurements. However, with recent developments in US techniques and frequent performance of spinal cord US, the necessity of a new cutoff value for thickness at the submillimeter level has emerged for spinal cord US in young infants $[10,30]$. To overcome possible submillimeter measurement errors in examinations, we included as many exams as we could from a long study period and found a tendency for thickness to change according to age and the presence of a lipoma. A third limitation is that a relatively small number of infants were included in the 7to 11-month-old group, because US and MRI were only performed upon clinical demand. In addition, there might be concerns that the last US exams were possibly influenced by previous exams because the US performers were not blinded to previous US results. However, the measurements of filum terminale thickness are unlikely to have been strongly influenced by previous results because the filum thickness was objectively measured in the most clearly visualized areas, and this was not a subjective analysis. Regardless, our study is the first to address the optimal timing for screening spinal cord US to detect filum terminale lipoma in infants under 1 year of age. Further prospective investigations, including those with even number of children in each age group, are needed to substantiate these findings. 
In conclusion, the thickness of the filum terminale increased with age in young infants with filum terminale lipoma. The 4- to 6-monthold period seems to be the optimal time for infants to undergo screening spinal cord US to diagnose filum terminale lipoma, with a cutoff thickness of $1.1 \mathrm{~mm}$. Spinal cord US is an effective screening examination for young infants who need to undergo spinal MRI to evaluate the presence of intraspinal abnormalities.

ORCID: Salman S. Albakheet: https://orcid.org/0000-0001-5998-0355; Haesung Yoon: https://orcid.org/0000-0003-0581-8656; Mi-Jung Lee: https://orcid.org/0000-00033244-9171; Myung-Joon Kim: https://orcid.org/0000-0002-4608-0275; Kyu-Won Shim: https://orcid.org/0000-0002-9441-7354; Ho Sun Eun: https://orcid.org/00000001-7212-0341; Kyunghwa Han: https://orcid.org/0000-0002-5687-7237; Hyun Joo Shin: https://orcid.org/0000-0002-7462-2609

\section{Author Contributions}

Conceptualization: Shin HJ, Lee MJ. Data acquisition: Albakheet SS, Shin HJ, Lee MJ, Yoon H. Data analysis or interpretation: Shin HJ, Lee MJ, Yoon H, Han K. Drafting of the manuscript: Shin HJ, Albakheet SS, Lee MJ, Yoon H. Critical revision of the manuscript: Shin HJ, Albakheet SS, Lee MJ, Yoon H, Kim MJ, Park EK, Shim KW, Kim DS, Eun HS. Approval of the final version of the manuscript: all authors.

\section{Conflict of Interest}

No potential conflict of interest relevant to this article was reported.

\section{References}

1. Finn MA, Walker ML. Spinal lipomas: clinical spectrum, embryology, and treatment. Neurosurg Focus 2007;23:E10.

2. Hansasuta A, Tubbs RS, Oakes WJ. Filum terminale fusion and dural sac termination: study in 27 cadavers. Pediatr Neurosurg 1999;30:176-179.

3. Altman NR, Altman DH. MR imaging of spinal dysraphism. AJNR Am J Neuroradiol 1987;8:533-538.

4. Raghavan N, Barkovich AJ, Edwards M, Norman D. MR imaging in the tethered spinal cord syndrome. AJR Am J Roentgenol 1989; 152:843-852.

5. Tu A, Steinbok P. Occult tethered cord syndrome: a review. Childs Nerv Syst 2013;29:1635-1640.

6. Steinbok P, MacNeily AE, Hengel AR, Afshar K, Landgraf JM, Hader $W$, et al. Filum section for urinary incontinence in children with occult tethered cord syndrome: a randomized, controlled pilot study. J Urol 2016;195:1183-1188.

7. Yamada S, Zinke DE, Sanders D. Pathophysiology of "tethered cord syndrome". J Neurosurg 1981;54:494-503.

8. Bulsara KR, Zomorodi AR, Villavicencio AT, Fuchs H, George TM. Clinical outcome differences for lipomyelomeningoceles, intraspinal lipomas, and lipomas of the filum terminale. Neurosurg Rev 2001;24:192-194.

9. Lode HM, Deeg KH, Krauss J. Spinal sonography in infants with cutaneous birth markers in the lumbo-sacral region: an important sign of occult spinal dysrhaphism and tethered cord. Ultraschall Med 2008;29 Suppl 5:281-288.

10. Shin HJ, Kim MJ, Lee HS, Kim HG, Lee MJ. Optimal filum terminale thickness cutoff value on sonography for lipoma screening in young children. J Ultrasound Med 2015;34:1943-1949.

11. Al-Omari MH, Eloqayli HM, Qudseih HM, Al-Shinag MK. Isolated lipoma of filum terminale in adults: MRI findings and clinical correlation. J Med Imaging Radiat Oncol 2011;55:286-290.

12. Hughes JA, De Bruyn R, Patel K, Thompson D. Evaluation of spinal ultrasound in spinal dysraphism. Clin Radiol 2003;58:227-233.

13. Lowe LH, Johanek AJ, Moore CW. Sonography of the neonatal spine: part 1, Normal anatomy, imaging pitfalls, and variations that may simulate disorders. AJR Am J Roentgenol 2007;188:733-738.

14. Lowe LH, Johanek AJ, Moore CW. Sonography of the neonatal spine: part 2, Spinal disorders. AJR Am J Roentgenol 2007;188:739744.

15. Azzoni R, Gerevini S, Cabitza P. Spinal cord sonography in newborns: anatomy and diseases. J Pediatr Orthop B 2005;14:185188.

16. McLendon RE, Oakes WJ, Heinz ER, Yeates AE, Burger PC. Adipose tissue in the filum terminale: a computed tomographic finding that may indicate tethering of the spinal cord. Neurosurgery 1988;22:873-876.

17. Saker E, Henry BM, Tomaszewski KA, Loukas M, Iwanaga J, Oskouian RJ, et al. The filum terminale internum and externum: a comprehensive review. J Clin Neurosci 2017;40:6-13.

18. Schnitzlein HN. Basic and clinical anatomy of the spine, spinal cord, and ANS. Clin Anat 1998;11:141.

19. Usami $K$, Lallemant P, Roujeau T, James S, Beccaria $K$, Levy $R$, et al. Spinal lipoma of the filum terminale: review of 174 consecutive patients. Childs Nerv Syst 2016;32:1265-1272.

20. Cornette L, Verpoorten C, Lagae L, Van Calenbergh F, Plets C, Vereecken $R$, et al. Tethered cord syndrome in occult spinal dysraphism: timing and outcome of surgical release. Neurology 1998;50:1761-1765.

21. Tortori-Donati P, Rossi A, Cama A. Spinal dysraphism: a review of neuroradiological features with embryological correlations and proposal for a new classification. Neuroradiology 2000;42:471491.

22. Xenos C, Sgouros S, Walsh R, Hockley A. Spinal lipomas in children. Pediatr Neurosurg 2000;32:295-307.

23. Bulsara KR, Zomorodi AR, Enterline DS, George TM. The value of magnetic resonance imaging in the evaluation of fatty filum terminale. Neurosurgery 2004;54:375-379.

24. Hayashi T, Kimiwada T, Kohama M, Shirane R, Tominaga T. Minimally 
invasive surgical approach to filum lipoma. Neurol Med Chir (Tokyo) 2018;58:132-137.

25. Ausili E, Maresca G, Massimi L, Morgante L, Romagnoli C, Rendeli C. Occult spinal dysraphisms in newborns with skin markers: role of ultrasonography and magnetic resonance imaging. Childs Nerv Syst 2018;34:285-291.

26. Korsvik HE, Keller MS. Sonography of occult dysraphism in neonates and infants with MR imaging correlation. Radiographics 1992;12:297-306.

27. Yundt KD, Park TS, Kaufman BA. Normal diameter of filum terminale in children: in vivo measurement. Pediatr Neurosurg 1997;27:257-
259.

28. Bao N, Chen ZH, Gu S, Chen QM, Jin HM, Shi CR. Tight filum terminale syndrome in children: analysis based on positioning of the conus and absence or presence of lumbosacral lipoma. Childs Nerv Syst 2007;23:1129-1134.

29. Deeg KH, Lode HM, Gassner I. Spinal sonography in newborns and infants--Part I: method, normal anatomy and indications. Ultraschall Med 2007;28:507-517.

30. Oh JE, Lim GY, Kim HW, Kim SY. Filum terminale lipoma revealed by screening spinal ultrasonography in infants with simple sacral dimple. Childs Nerv Syst 2020;36:1037-1042. 